\title{
ESTUDO DE CASO SOBRE INOVAÇÃO GERENCIAL EM UM MEIO DE HOSPEDAGEM NO DESTINO TURÍSTICO DA SERRA DO CIPÓ
}

Larissa Costa Monteiro De Barros ${ }^{1}$

Daniel Paulino Teixeira Lopes ${ }^{1}$

Glauciene Silva Martins ${ }^{1}$

${ }^{1}$ Centro Federal de Educação Tecnológica de Minas Gerais 


\section{ESTUDO DE CASO SOBRE INOVAÇÃO GERENCIAL EM UM MEIO DE HOSPEDAGEM NO DESTINO TURÍSTICO DA SERRA DO CIPÓ}

Resumo: Este artigo tem por objetivo apresentar um estudo de caso sobre como ocorrem inovações gerenciais em um meio de hospedagem localizado na Serra do Cipó. Foram discutidos conceitos de inovação, tipos de inovação, principalmente, inovação gerencial, bem como o processo de implantação, seja pela sua criação ou adoção, e os fatores determinantes (individual, intraorganizacional e macroambiental) para a tomada de decisão ao introduzi-la. Optou-se pela realização de uma pesquisa qualitativa por meio de estudo de caso, baseado em entrevistas semiestruturadas com gestores de um meio de hospedagem, observação não participante e análise de documentos. Os resultados trazem a descrição do caso, as percepções sobre inovação gerencial na pousada, os fatores determinantes que levaram à adoção ou à não adoção de dada inovação, e as consequências de cada decisão. Os resultados mais notórios sugerem a pouca adoção de inovação gerencial, determinada principalmente pelo porte do estabelecimento.

Palavras-chave: Inovação Gerencial. Inovação Organizacional. Determinantes da Inovação. Meios de Hospedagem.

\section{$1 \quad$ Introdução}

A inovação é um assunto muito discutido no século XXI por propiciar o desenvolvimento da sociedade e possivelmente um aumento de competitividade no mercado. Segundo Tidd e Bessant (2015), a inovação é movida pela habilidade de estabelecer relações, detectar oportunidades e tirar proveito delas, ou seja, é muito mais do que uma mera invenção. Assim, trata-se de relacionar informações já disponíveis a fim de abrir novos mercados ou criar novas formas de servir a mercados já estabelecidos e maduros e, por fim, gozar dos benefícios proporcionados pela efetivação.

Seguindo essa linha de raciocínio, é visível que a inovação é um conceito complexo, visto que envolve um alvo em constante movimento (TIDD; BESSANT, 2015). Por ter o objeto de estudo abstrato, a inovação tem várias dimensões dentre as quais: quanto à amplitude - setorial, regional, global - quanto ao grau de novidade - incremental, radical - e quanto ao tipo - produto, processo, marketing, organizacional (i.e. gerencial) (OECD, 2005). A inovação em produto aprimora produtos já existentes mudando as características funcionais como materiais, componentes ou cria um bem inédito. Por sua vez, a inovação em processo modifica o método de produção e distribuição, por exemplo, técnicas, equipamentos, softwares. Já a inovação em marketing reestrutura o conceito, estratégia ou estética do produto. Finalmente, a inovação gerencial, alvo desse estudo, é resultado de decisões estratégicas dos diretores que envolvem técnicas de gestão, gestão ambiental, gestão do trabalho e gestão de relações externas, antes não utilizadas pelas empresas (OECD, 2005, IBGE, 2014).

Como a inovação gerencial envolve a gestão de diversos setores, ela é de suma importância para as organizações combaterem a entropia e permanecerem, crescerem no 
mercado. Assim, destaques tecnológicos, recursos e capacidades únicas (como uma engenharia de negócios inigualável) podem ser determinantes para a sobrevivência de uma empresa, ou podem ser a chance de sair à frente das demais concorrentes para aquelas empresas já estabilizadas.

A inovação gerencial tem inúmeros obstáculos, tanto de ser pensada e planejada, quanto de ser implementada. As pesquisas apontam, de um lado, que há a conquista da abertura das empresas sobre parcerias, estratégias e decisões, mensuração do que seria considerado como novo, o reconhecimento do novo como inovação e a determinação e retenção do valor do experimentado e testado (DODGSON; GANN; PHILLIPS, 2014). De outro lado, na implementação, os gestores lidam com o apoio (ou não) dos funcionários, explicação das novas medidas adotadas e o equilíbrio entre produzir valor por meio de negócios existentes que geram os recursos, que permitem criar oportunidades para desenvolver novas formas de criar, entregar e capturar valor (DODGSON; GANN; PHILLIPS, 2014). Devido a essa dificuldade de implementação da inovação gerencial, fez-se interessante o seguinte questionamento: Como se dão os processos de inovação gerencial em meios de hospedagem de pequeno porte na Serra do Cipó?

Tendo em vista os conceitos já expostos, o objetivo deste artigo é apresentar um estudo de caso sobre como ocorrem inovações gerenciais em um meio de hospedagem localizado na Serra do Cipó. Devido à escassez de pesquisas nos meios de hospedagem da Serra do Cipó, o estudo focou em uma dessas organizações. A região da Serra do Cipó é uma das principais regiões turísticas de Minas Gerais, envolvendo em sua dinâmica diversas pousadas e acomodações, viabilizando uma análise dos processos de inovação gerencial tendo como base diferentes perspectivas.

Este artigo está estruturado da seguinte maneira: segue-se a esta introdução o referencial teórico, que aborda conceitos de inovação, tipos de inovação, inovação gerencial, em especial, nos meios de hospedagem, mensuração e obstáculos e impactos. Na terceira seção, a metodologia caracterizará os procedimentos usados a exemplo do tipo de entrevista. Posteriormente, a análise e a discussão de resultado tratarão do que foi observado ao longo de toda a pesquisa, levando em consideração o contato direto e indireto com o objeto de estudo e os sujeitos em questão. Por fim, a conclusão resumirá o estudo e indicará novas oportunidades de pesquisas ponderadas.

\section{Inovação - breve conceituação e revisão de tipologias}

Uma das primeiras definições do termo inovação foi dada por Joseph Schumpeter (1934), que argumentava que a inovação consistia em novas combinações em um processo de destruição criativa, que é provocada pelo empreendedor. Refere-se às antigas tecnologias que são substituídas pelas novas tecnologias bem como às diversas combinações de fatores que impulsionariam o desenvolvimento econômico (TIDD; BESSANT, 2015). Essa definição Schumpeteriana gerou contraposição de Hansen e Wakonen (1997) apud Crossan e Apaydin (2010), os quais descaracterizaram a inovação como uma mera destruição criativa - relacionase muito mais com o termo invenção. Hansen e Wakonen (1997) descreveram, assim, invenção como uma criação intencional de algo novo, que tem uma natureza benéfica, e inovação como uma criação com teor prático, em que para ser validada deve ser aplicada.

Tendo em vista a contraposição de Schumpeter (1934) e Hansen e Wakonen (1997) citados por Crossan e Apydin (2010), Drucker (1985) dista um pouco do termo invenção para definir inovação. Esse autor tem uma interpretação mais focada nos negócios ao defender: 
"Inovação é a ferramenta específica dos empreendedores, o meio pelo qual exploram as mudanças como oportunidades para um negócio ou serviço diferente." Ou seja, a inovação na concepção de Drucker abrange o nicho específico das pessoas que querem abrir o negócio próprio ou que já têm esse negócio e querem aprimorá-lo.

A inovação é segmentada em várias tipologias, em que quatro delas serão abordadas neste artigo, a fim de delimitar melhor o objeto de estudo de cada uma. A primeira tipologia, inovação em produto, consiste em uma modificação (incremental ou radical) de um bem ou serviço, em que as características funcionais são alteradas (OECD, 2005). Assim, há a mudança do material, dos componentes, da forma, visando o aprimoramento do bem em questão. Segundo a Pesquisa de Inovação - PINTEC 2014 (IBGE, 2016), a inovação em produto é implementada mais facilmente no setor industrial, porque a clareza a respeito da linha de produção, das estratégias de produção é maior. Isso justifica a estatística 18,3\% das empresas industriais lançaram produtos novos ou aprimorados em 2014.

A segunda tipologia, inovação em processo traduz-se na transformação no modo de criar e disponibilizar o produto (TIDD; BESSANT, 2015). Com isso, as técnicas de produção, os equipamentos, os softwares, o custo unitário de distribuição são melhorados para aumentar a capacidade de mobilização financeira e de materiais e consequentemente aumentar a competitividade da organização no mercado.

A terceira tipologia, inovação em marketing, assim como a inovação em produto, é centrada na demanda dos clientes. Por isso, ela está ligada à pesquisa de mercado, ao design dos produtos ou serviços, à embalagem, aos canais de venda para melhor atender os desejos dos consumidores (OECD, 2005). Um exemplo de inovação de marketing é o Omnichannel, em que a empresa está presente em todos os canais de venda simultaneamente dialogando com o potencial comprador, afinal a trajetória que ele segue desde a pesquisa até a compra fica cada vez mais complexa devido às múltiplas possibilidades (VERHOEF et al., 2015).

Diferentemente da inovação em processo, a quarta tipologia inovação gerencial (ou inovação organizacional) é resultado de decisões estratégicas tomadas pela direção (IBGE, 2016). Tais decisões contribuem com a redução de custos, com a reengenharia de negócios, com a maior qualificação da cadeia de fornecedores, com a produção enxuta e eficaz e com o gerenciamento de pessoas de qualidade (OECD, 2005). A inovação em processo, não raro, é confundida com a inovação gerencial, visto que ambas são focadas na organização e são mais abstratas.

Recentemente, essas tipologias passaram a serem consideradas pela quarta edição do Manual de Oslo 2018 como "inovação em produto" ou como "inovação em processos de negócio" (OECD, 2018). Enquanto o conceito de inovação em produto se manteve e incorporou em certa medida, o de marketing, as inovações em processos de negócio passaram a englobar: Processo de produção de bens e serviços; Distribuição e logística; Marketing, vendas e serviços pós-venda; Sistemas de TIC; Administração e gestão; Serviços de engenharia e técnicos; Desenvolvimento de produtos e processos de negócio.

Mais especificamente, inovação na "Administração e gestão" inclui novidades na gestão estratégica e geral do negócio; governança corporativa (jurídica, planejamento e relações públicas); contabilidade, auditoria, pagamentos e outras financeiras/seguros; gestão de RH; compras e gestão dos relacionamentos externos com fornecedores (alianças etc.). Portanto, é importante ressaltar que as definições e abrangências das tipologias modificam-se ao longo do tempo. Essas modificações são apontadas no Manual de Oslo (OECD, 2018), conforme o Quadro 1. 
Quadro 1. Tipologias de inovação no Manual de Oslo (2005 e 2018)

\begin{tabular}{|c|c|c|c|}
\hline \multicolumn{2}{|r|}{ Manual de Oslo 2005} & \multirow{2}{*}{ Manual de Oslo 2018} & \multirow{2}{*}{ Diferenças entre as publicações } \\
\hline Tipo & Subcomponentes & & \\
\hline 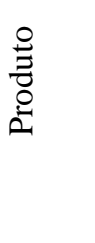 & $\begin{array}{l}\text { Mercadorias } \\
\text { Serviços }\end{array}$ & $\begin{array}{l}\text { Mercadorias e serviços } \\
\text { incluindo captura de } \\
\text { conhecimento, produtos e } \\
\text { combinação disso. Inclui as } \\
\text { características de design das } \\
\text { mercadorias e dos serviços }\end{array}$ & $\begin{array}{l}\text { Serviços de captura de conhecimento, } \\
\text { produtos e combinação no Manual de } \\
\text { Oslo de } 2005 \text { pertencia a administração } \\
\text { e gestão }\end{array}$ \\
\hline $\begin{array}{l}0 \\
0 \\
0 \\
0 \\
0 \\
0\end{array}$ & $\begin{array}{l}\text { Produção } \\
\text { Entrega e logística } \\
\text { Serviços auxiliares } \\
\text { incluindo compras, } \\
\text { contabilidade e serviços } \\
\text { ICT }\end{array}$ & $\begin{array}{l}\text { Produção, distribuição e } \\
\text { logística, sistemas de } \\
\text { informação e comunicação }\end{array}$ & $\begin{array}{l}\text { No Manual de Oslo de } 2005 \text { serviços } \\
\text { auxiliares pertencia a administração/ } \\
\text { gestão }\end{array}$ \\
\hline 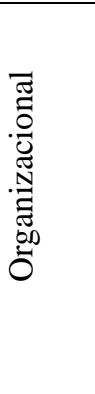 & $\begin{array}{l}\text { Práticas de negócios } \\
\text { Organização do trabalho } \\
\text { (distribuição de } \\
\text { responsabilidades, poder } \\
\text { de decisão) } \\
\text { Relações externas }\end{array}$ & Administração e gestão & $\begin{array}{l}\text { No Manual de Oslo de } 2005 \text { as } \\
\text { inovações organizacionais pertenciam à } \\
\text { administração e à gestão. Já no Manual } \\
\text { de Oslo de } 2018 \text { elas são as } \\
\text { subcategorias a,b e f. } \\
\text { Serviços auxiliares, que na edição } \\
\text { anterior era incluso em inovação por } \\
\text { processo, agora pertence à administração } \\
\text { e gestão (subcategorias c, d e e) }\end{array}$ \\
\hline 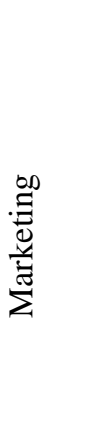 & $\begin{array}{l}\text { Design de produtos } \\
\text { Colocação e embalagem } \\
\text { do produto } \\
\text { Posicionamento do } \\
\text { produto } \\
\text { Estabelecimento de preço }\end{array}$ & $\begin{array}{l}\text { Marketing, vendas e suporte } \\
\text { de pós-vendas }\end{array}$ & $\begin{array}{l}\text { No Manual de Oslo de 2005, inovação } \\
\text { em marketing está incluso nas } \\
\text { subcategorias a e b. Além disso, ele não } \\
\text { inclui inovação em vendas, pós-vendas } \\
\text { de serviços e outras funções de suporte } \\
\text { ao cliente. } \\
\text { No Manual de Oslo de } 2018 \text {, as } \\
\text { inovações relacionadas ao design de } \\
\text { produto estão inclusas na inovação de } \\
\text { produto. }\end{array}$ \\
\hline$\frac{\mathbb{Z}}{\mathrm{z}}$ & N/A & $\begin{array}{l}\text { Desenvolvimento de produto } \\
\text { e processos de negócio }\end{array}$ & $\begin{array}{l}\text { Não é considerado no Manual de Oslo } \\
\text { de } 2005 \text {, a maioria provavelmente vem } \\
\text { sendo relatado como inovação de } \\
\text { processo }\end{array}$ \\
\hline
\end{tabular}

Fonte: Traduzido de OECD (2018)

Nota. A pesquisa apresentada neste artigo foi realizada em período anterior à publicação da nova edição do Manual de Oslo.

A inovação organizacional (ou gerencial, nos termos deste artigo), centra-se na administração da empresa e será mais detalhada na seção seguinte quanto aos seus conceitos, determinantes, processo de adoção, obstáculos e consequências. 


\section{Inovação Gerencial}

As principais discussões relativamente mais recentes sobre inovação gerencial - nas quais a pesquisa apresentada neste artigo foi baseada - podem ser encontradas nos frameworks discutidos por Birkinshaw et al. (2008), Volberda et al. (2013) e Damanpour (2014). Fica evidente nas análises desses e de outros autores que a inovação gerencial, na maioria das vezes, não é tecnológica, pois não depende de bens concretos e sim de conhecimentos e práticas mais abstratas.

A inovação gerencial se caracteriza como resultado de decisões estratégicas de "cima para baixo" ou de iniciativas "de baixo para cima", que envolvem técnicas de gestão, gestão ambiental, gestão do trabalho e gestão de relações externas, antes não utilizadas pelas empresas (IBGE, 2016). Visto que a inovação gerencial depende da gestão de inúmeras áreas e, consequentemente, da decisão dos gestores acerca do rumo que cada área irá prosseguir, para que um gestor decida implantá-la, ele/ela pode ser influenciado por vários fatores que determinam a adoção de tal inovação (LOPES et al., 2018).

Esses fatores determinantes podem ser divididos em três níveis: macroambiental e interorganizacional, intraorganizacional e individual (CROSSAN; APAYDIN, 2010; VOLBERDA et al., 2013; LOPES et al., 2018). O nível macroambiental e interorganizacional abrange a localização geográfica da organização, a estrutura do mercado, características do setor, tipo de tecnologia e de mercado, incerteza e complexidade. Assim, esse nível influencia na decisão do gestor com acontecimentos externos à organização, ou seja, algo que a empresa não tem controle. Já o nível intraorganizacional abrange o tipo de organização, tempo de existência, interações, interesses, estruturas de poder, coalizações, falhas cometidas anteriormente, histórico de desempenho, alavancas gerenciais e processos de negócios. Esse nível intraorganizacional é o que mais reflete a realidade da organização. Além disso, ele permite uma análise mais detalhada das condições e limites da organização. Por sua vez, o nível individual abarca a idade, o profissionalismo, a qualificação do gestor, quanto tempo ele está no cargo e a inovação de liderança que ele propôs. Com isso, o nível individual é o mais específico e leva em consideração a posição do gestor e seu histórico a fim de conferir a credibilidade de ele ou ela tomar as decisões (CROSSAN; APAYDIN, 2010; LOPES et al., 2018).

Diante do exposto, os componentes de cada nível têm sua devida importância na implementação de cada inovação gerencial. Faz-se importante esclarecer também a diferença de criar, difundir e adotar certa inovação. Ao criar a inovação gerencial, o foco é no desenvolvimento do projeto e com que rapidez e eficácia ele ocorre. Já ao difundir, o foco muda para a disseminação do projeto, levando em consideração o contexto em que ele está inserido e a velocidade que se da à disseminação. Tal disseminação pode ser intrafronteiras (propagação dentro de um setor, por exemplo) ou extrafronteiras (em um ramo específico ou até globalmente), dependendo da fonte dos custos, da intensidade da inovação, dos valores, da confiança e das normas da empresa. Por fim, ao adotar a inovação, o foco é na assimilação e avaliação da resposta ao problema que deveria ser resolvido. (LOPES et al., 2018).

A adoção de inovações gerenciais necessita de uma maior cautela por parte das organizações. Afinal, a assimilação gera um impacto em toda a estrutura empresarial, que refletirá nas operações e na receita da empresa. Para que haja a adoção, a inovação já deve ter sido criada e a empresa já deve ter um estudo prévio sobre ela. A partir daí, a organização pode mudar suas rotinas e regras a fim de implementar tal inovação gerencial. Esse processo ocorre de maneira lenta, incerta e idiossincrática, se comparado com a adoção de uma

DOI: $10.14211 /$ xi-egepe-118110 
inovação tecnológica. Após a lenta assimilação, a empresa vive a fase de legitimação, que reflete o engajamento dos funcionários, a solução do problema identificado e o fortalecimento ou enfraquecimento da inovação gerencial (CROSSAN; APAYDIN, 2010; LOPES et al., 2017).

Tendo em vista que as fases de adoção da inovação gerencial movimentam muito as atividades de uma organização, existem inúmeros obstáculos nesse processo. Tais obstáculos serão explicitados na sessão seguinte.

\subsection{Obstáculos}

Os obstáculos enfrentados para a implementação de uma inovação gerencial estão ligados diretamente à natureza de tal inovação. Ela está sempre mudando e tem um caráter abstrato, isso pode dificultar a percepção dos benefícios advindos em longo prazo, uma vez que o valor não é apreciado no momento do investimento (DODGSON; GANN; PHILLIPS, 2014). Além disso, a inovação pode acontecer em uma velocidade notável, sendo um empecilho tanto para os que têm de se adaptar as novas regras, quanto aos que estudam tal fenômeno. Especificamente para os que estudam tal fenômeno outra contrariedade é determinar e reter o valor do que foi testado enquanto mantém o interesse no novo e emergente com suficiente cautela (DODGSON; GANN; PHILLIPS, 2014). Ou seja, é conciliar o que já foi estudado com o que está surgindo e crescendo em termos de inovação.

Como os profissionais relacionados à área da inovação devem ter certos conhecimentos e habilidades para lidar com a frequente mudança e com as oportunidades antes desconhecidas, surgem desafios para a organização (IBGE, 2016). Esses desafios são os altos custos do desenvolvimento dos funcionários e a escassez de mão de obra qualificada para tomar decisões em um ambiente de alto risco e incerteza (IBGE, 2016; DODGSON; GANN; PHILLIPS, 2014).

Outro impedimento da atividade inovativa é a escassez de fontes apropriadas de financiamento. Como a inovação envolve um risco econômico considerável para as organizações, muitas optam por continuar com a mesma estrutura de serviço, com as mesmas relações externas e com os mesmos funcionários. Afinal, isso pode ser mais cômodo e no curto prazo pode parecer mais benéfico. No Brasil, algumas soluções para tal obstáculo de financiamento foram propostas pelo governo: incentivo fiscal à $\mathrm{P} \& \mathrm{D}$. No entanto, o financiamento para inovações gerenciais ainda é precário, visto que nos anos de 2012 a 2014, esse auxilio do governo foi utilizado principalmente para aquisições de máquinas e equipamentos (IBGE, 2016).

Diante do exposto, é válido esclarecer que mesmo que a organização aproveite o financiamento do governo, consiga mão de obra qualificada e diminua ao máximo os riscos econômicos, ainda há um obstáculo fundamental: a rigidez organizacional (IBGE, 2016). Essa inflexibilidade dentro de uma instituição prejudica um ambiente e uma cultura que aceite as mudanças e prezam pela constante evolução da empresa. Logo, percebe-se que um passo essencial em uma organização que almeja inovar é a abertura para a mudança e a eliminação de funcionários "glóbulos brancos" - geralmente o setor financeiro e jurídico que impedem qualquer ação inovativa (CAETANO, 2018).

De modo geral, os principais obstáculos à inovação de acordo com o Manual de Oslo (OECD, 2018) são a política de mercado da firma, políticas públicas incluindo regulamentações, o meio ambiente e a sociedade. Os conjuntos de obstáculos discutidos nesta seção são representados no Quadro 2. 


\section{Quadro 2. Obstáculos à inovação gerencial}

\begin{tabular}{|l|l|}
\hline Obstáculo Geral & Obstáculo Específico \\
\hline Política de Mercado & $\begin{array}{l}\text { Consumidores nacionais } \\
\text { Acesso ao mercado internacional } \\
\text { Fornecedores e cadeia de valor } \\
\text { Disponibilidade e custo de mão de obra qualificada } \\
\text { Disponibilidade e custo de capital } \\
\text { Concorrentes } \\
\text { Padronização } \\
\\
\text { Conhecimento de mercado } \\
\text { Plataformas digitais }\end{array}$ \\
\hline Política Pública & Regulamentações \\
& Funcionamento dos tribunais e aplicação das regras \\
& Impostos \\
& Destinação do capital público (prioridades e níveis) \\
& Suporte do governo à inovação \\
& Demanda do governo por inovação \\
& Infraestrutura pública \\
& Estabilidade política em geral \\
\hline Sociedade & Resposta do consumidor à inovação \\
& Opinião pública favorável a respeito da inovação \\
& Nível de confiança nos atores da economia \\
\hline
\end{tabular}

Fonte: Manual de Oslo (OECD, 2018, p. 160).

Por fim, uma dificuldade em entender esses obstáculos passa por diferenciar a inovação de uma mera mudança. De acordo com o Manual de Oslo, a interrupção do uso de algo, a reposição ou extensão de capital, as mudanças resultantes só de alterações de preços, a personalização, as mudanças sazonais regulares ou cíclicas e a comercialização de produtos novos ou substancialmente melhorados não constituem uma inovação.

Nota-se, portanto, a importância de se identificarem os obstáculos à inovação, tanto tecnológica, quanto gerencial. Além disso, é relevante discutir as consequências dessas inovações, como se observa a seguir.

\subsection{Consequências}

A adoção de inovações reflete vários desdobramentos ao produto ou serviço ofertado pela empresa, ao mercado em que ela está inserida, ao processo de produção de tal produto ou serviço, às rotinas da instituição, às estruturas de trabalho, ao enquadramento em regulamentos e normas, ao meio ambiente, à saúde e à segurança - tanto dos funcionários, quanto de toda a população dependendo do tipo de inovação (IBGE, 2016). Tais desdobramentos são de difícil mensuração, afinal, por vezes, há gastos os quais as empresas não registram em uma conta contábil específica (os gastos que mais contribuem para mensuração são de $\mathrm{P} \& \mathrm{D}$, que normalmente têm uma conta própria). Por isso, não se sabe precisamente o impacto desses desdobramentos frente aos investimentos realizados.

Apesar de a inovação não ser, normalmente, integrante da contabilidade geral das empresas, ela é verificada quando os efeitos das atividades inovativas já estão concretizados e 
podem ser perceptíveis (OECD, 2005). Esses efeitos são visíveis por meio do aumento da capacidade competitiva, do valor adicionado ao produto ou serviço, da conquista de mercados, da redução do impacto no meio ambiente, da redução dos custos com a produção e dos impactos sobre o faturamento, sobre o ciclo de vida do produto ou serviço, sobre a geração de emprego e sobre a eficiência - se uma inovação gerencial é adotada e obtém-se sucesso, a eficiência aumenta. (OECD, 2005; IBGE, 2016).

Restringindo-se às consequências da inovação gerencial, as principais negativas são perda de controle do valor do conhecimento, perda de controle da estratégia da organização, dificuldade de achar a parceria correta, lacuna de recursos financeiros, preocupação com o vazamento de informações e dificuldade de estabelecer confiança. Já as principais positivas são aumento da capacidade de absorção de conhecimento da empresa, melhora no processamento e análise de dados, melhora no compartilhamento e na transferência de conhecimento com outras organizações, melhora na eficiência e na funcionalidade da cadeia de valor, melhora da comunicação intraorganizacional, desenvolvimento de novas relações com entidades externas (como outras firmas e universidades) e aumento da adaptabilidade às mudanças (OECD, 2018).

Diante do exposto, é notável que a inovação pode melhorar consideravelmente o cenário das organizações, por isso, há a necessidade de proteger a inovação adotada de cópias dos concorrentes. Essa proteção pode ser feita por meio da complexidade no desenho do produto, do segredo industrial ou comercial (acordo confidencial), do tempo de liderança sobre os competidores, das patentes e registros e do direito autoral (IBGE, 2016).

A partir dessa discussão teórica sobre inovação e suas tipologias, inovação gerencial e seus determinantes, obstáculos e consequências, a seção seguinte detalha os métodos utilizados para desenvolver a pesquisa.

\section{Método de Pesquisa}

Optou-se pelo método estudo de caso único que, segundo Gil (1999) e Creswell (2007), deve ser realizado de modo profundo e exaustivo, a partir da análise de um (ou poucos) objeto de maneira ampla e detalhada. Assim, preza-se pela descrição detalhada do cenário, das pessoas e dos dados.

Seguindo essa lógica de detalhamento, o tipo da pesquisa foi exploratório, em que o produto final deste processo passa a ser um problema mais esclarecido (CREWELL, 2007). Ademais, esse produto final visa à formulação de novos problemas e hipóteses a serem pesquisados em estudos posteriores. O critério de tempo de existência foi levado em consideração para selecionar o meio de hospedagem pesquisado (foi um dos primeiros a se instalar no distrito, assim um maior histórico poderia ser explorado) e seus respectivos funcionários entrevistados. A fim de manter o sigilo e a identidade dos participantes, foram usados nomes fictícios tanto para pousada quanto para os entrevistados.

Visto que o desenvolvimento dessa pesquisa pressupõe um estudo de caso exploratório, a abordagem foi qualitativa. Com isso, não houve necessidade de instrumental estatístico para análise dos dados (CRESWELL, 2007), o que justifica o caráter profundo das entrevistas semiestruturadas. Essa abordagem qualitativa normalmente inclui a ida do pesquisador ao local, tanto para realizar tais entrevistas, quanto para observar a rotina, as pessoas e o local, dentre outros aspectos. Outras características da abordagem qualitativa, segundo Creswell (2007) são: é um estudo emergente, pois demandas e indagações podem ser alteradas ao longo do estudo; é interpretativa, afinal a pesquisa está inserida em um 
determinado contexto histórico; é carregada de valores, uma vez que o pessoal é inseparável do pesquisador e é repleta de um raciocínio complexo, multifacetado, interativo e simultâneo.

Tendo isso em vista, uma pesquisa piloto foi realizada em um meio de hospedagem em Belo Horizonte. No piloto, um pré-teste do roteiro de entrevista foi realizado em ambiente similar à Pousada Cipó dois meses antes da ida ao distrito. Essa experiência validou o roteiro e gerou pequenas adaptações às perguntas, a fim de focar mais na inovação gerencial. Inicialmente, o propósito era entrevistar seis fundadores de pousadas. No entanto, devido à dificuldade de agendar as entrevistas, o estudo se restringiu à Pousada Cipó. As entrevistas semiestruturadas foram feitas com três pessoas e têm caráter confidencial, conforme o Quadro 3 .

Quadro 3. Cargos dos entrevistados

\begin{tabular}{|l|l|}
\hline Nome fictício & Cargo \\
\hline Kevin & Fundador, gestor \\
\hline Aurélio & Publicitário \\
\hline Amadeu & Administrador, Recepcionista \\
\hline
\end{tabular}

Fonte: dados da pesquisa.

Todas as três entrevistas foram baseadas em um roteiro com pautas pré-definidas, em linha com a discussão teórica, porém com certa flexibilidade. A primeira entrevista, com o fundador, foi realizada no dia 07 de fevereiro de 2019 em sua propriedade localizada em Belo Horizonte. Já a segunda e a terceira entrevistas ocorreram no dia 08 de fevereiro de 2019 na Pousada Cipó (nome fictício), na Serra do Cipó.

Além das entrevistas, outros dados coletados por meio de documento e observação não participantes foram utilizados. O documento explorado foi o planejamento estratégico da instituição (power point feito pelo fundador) e a observação não participante pôde ser registrada por algumas imagens.

Os dados, com a transcrição das entrevistas e demais registros foram reorganizados conforme às categorias e subcategorias do Quadro 4.

Quadro 4. Categorias de análise

\begin{tabular}{|l|l|}
\hline Categorias & Subcategorias \\
\hline Descrição da pousada & Localização geográfica \\
& Número de acomodações \\
& Fundação \\
& Características físicas e gerenciais \\
\hline Inovação gerencial & Conceito \\
& $\begin{array}{l}\text { Histórico de inovações (na região, setor e estabelecimento) } \\
\text { Processo de adoção } \\
\text { Obstáculos }\end{array}$ \\
\hline Fatores determinantes & $\begin{array}{l}\text { Macroambiental e interorganizacional } \\
\text { Intraorganizacional } \\
\text { Individual }\end{array}$ \\
\hline Consequências & $\begin{array}{l}\text { Mensuração } \\
\text { Aumento da competitividade } \\
\text { Estruturação trabalho }\end{array}$ \\
\hline
\end{tabular}

Fonte: dados da pesquisa. 
Após essa reorganização, os dados foram analisados de acordo com a obtenção do sentido das informações e a reflexão do sentido global (CRESWELL, 2007). Em seguida, foram geradas descrições e, por fim, extraíram-se significados e expuseram-se lições aprendidas. Essas etapas da análise de dados podem ser vistas mais minuciosamente na próxima sessão.

\section{Análise dos Resultados}

Esta sessão está organizada seguindo o quadro expresso na Metodologia. Assim, inicialmente haverá a descrição do meio de hospedagem, incluindo a localização geográfica, o número de acomodações, a fundação, as características físicas e gerenciais e o histórico de inovações. Em segundo lugar, o conceito, o processo de adoção e os obstáculos da inovação gerencial serão discutidos, conforme as entrevistas realizadas. Em terceiro lugar, entrarão em pauta os fatores macroambientais e interorganizacionais, intraorganizacionais e individuais que auxiliaram nas decisões do gestor. Por fim, as consequências da adoção ou da não adoção da inovação serão expostas, tendo em vista a mensuração, o aumento da competitividade e a estruturação do trabalho.

\subsection{Descrição do caso - A Pousada Cipó como meio de hospedagem}

A Pousada Cipó - quinta pousada a ser construída na Serra do Cipó - foi fundada em 1983 por Kevin que, após a tentativa de empreender em Arraial D'ajuda, mudou o foco para o distrito da Serra do Cipó. Assim, ele iniciou sua construção com quatro chalés de acordo com o que foi projetado na planta chave (continha os detalhes de cada cômodo e as especificações de onde ficaria cada chalé). Atualmente, o meio de hospedagem tem 11 funcionários, recebe em maior quantidade turista com mais de 30 anos e disputa mercado principalmente com outros meios de hospedagem mais tradicionais (que já se instalaram há mais de 20 anos).

$\mathrm{Na}$ época da inauguração da Pousada o distrito não era desenvolvido, de modo que a água era escassa, a energia elétrica era precária e a comunicação era monopolizada por uma rede de telefonia. Além disso, comércios como farmácia e padaria eram ausentes, forçando a dependência de moradores e turistas de cidades próximas.

Como a Pousada Cipó localiza-se na Rodovia MG-10, km 99,5 no município Santana do Riacho, as principais cidades que auxiliavam os moradores e turistas eram Lagoa Santa e Belo Horizonte. Essa posição na MG-10 é privilegiada por estar a apenas 500m da Cachoeira Véu da Noiva, a 4,6km da Cachoeira Grande, a 4,6km da Cachoeira do Tome e a 5,1km da Cachoeira de Baixo. Ademais, fica perto das principais ruas que dão acesso aos outros atrativos.

A singularidade do estabelecimento e seu posicionamento no mercado não se restringem à localização, uma vez que conta com um enorme gramado, com "fogueiródromos" (espaço para fazer e acender fogueira), piscina, churrasqueira, salão de eventos, salão de yoga, refeitório e 19 chalés distribuídos em quatro estilos diferentes, representados a seguir: 


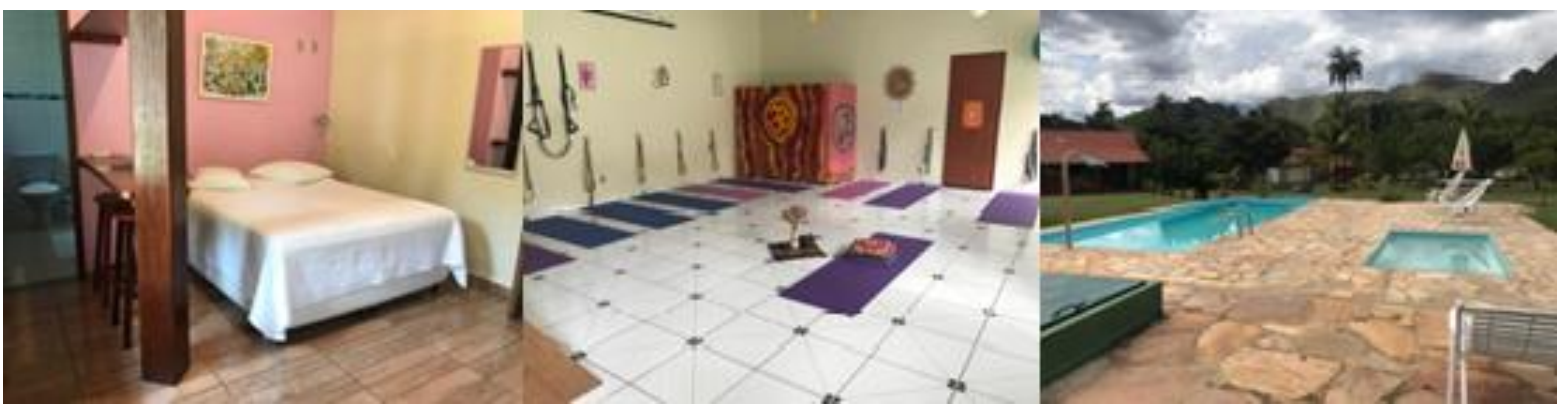

Figura 1. Espaços de acomodação, yoga e área de lazer.

Fonte: Dados da pesquisa.

O estilo dos chalés varia em Ecológico, Standard, Tijolinho e Chalezinho. Há equipamentos como televisão, frigobar e ar condicionado que são comuns em todos os chalés. Portanto, o que os diferenciam é a capacidade de hóspedes, o ambiente e algumas especialidades. O chalé Ecológico é amplo, moderno, tem uma varanda nos fundos em contato com a natureza, 1 cama de casal e 1 de solteiro. Do mesmo modo, o chalé Standard também tem 1 cama de casal e 1 de solteiro e possui uma mesa para refeições e/ou suporte. $\mathrm{O}$ chalé Tijolinho, por sua vez, suporta até 4 hóspedes, sendo indicado para famílias. Por fim, o Chalezinho é restrito ao casal e ainda não foi totalmente reformado.

Diante do exposto, os chalés com mesmo estilo ficam agrupados no mesmo setor. Vale ressaltar que todos têm uma boa acessibilidade à área de lazer da pousada. Essa área inclui a piscina, que tem acesso liberados aos hóspedes, churrasqueira, que é alugada por $\mathrm{R} \$ 40,00$ e o salão de Yoga, que oferece aulas por $\mathrm{R} \$ 25,00$.

Tendo em vista toda a estrutura da Pousada Cipó, o fundador relata que não pretende expandir muito, para não perder a cordialidade com os hóspedes e manter o controle. Assim, na próxima sessão serão aprofundadas as inovações realizadas até a entrevista e as possíveis inovações futuras.

\subsection{Inovação gerencial}

A administração da pousada é feita de maneira mais informal, em que os funcionários são predominantemente membros da família. Tanto o fundador, quanto os funcionários entrevistados enxergam a inovação como algo estritamente tecnológico, revelando uma aproximação do olhar Schumpeteriano da destruição criativa - as antigas tecnologias são substituídas pelas novas tecnologias.

Diante dessa perspectiva, Kevin afirmou acreditar que muita inovação vem da internet, que hoje é uma maneira de gestão e interliga o marketing de pousadas com o mundo todo. Apesar de não identificar as tipologias de inovação, segundo o Manual de Oslo 2018, o fundador relata mudanças às quais podem se enquadrar nas respectivas categorias.

Com o foco na inovação gerencial, percebem-se poucas implementações na pousada: adoção de gerenciador de pousadas (Desbravador), parceria com o Sebrae (para capacitar os funcionários) e o gerenciamento de uma conta específica para reformas.

O gerenciador de pousadas proporciona a facilidade na obtenção e análise de dados a respeito do cliente. Assim, ele fornece uma ficha dos hóspedes incluindo a procedência, a faixa etária, sexo, portanto, é uma base de informações. Essa inovação impactou a 
organização do trabalho, uma vez que os funcionários que faziam os cadastros e o preenchimento de dados passaram a desempenhar outra função. Já a parceria com o Sebrae modificou a rotina da pousada. Após os treinamentos, o "como fazer" dos funcionários foi adequado e melhorado. Por fim, o gerenciamento da conta contábil direcionada às reformas garantiu um fundo necessário para a obra, sem que houvesse maiores transtornos e dívidas.

Diante do exposto, percebe-se que todas as inovações gerenciais adotadas transformaram a organização do trabalho, ou seja, não houve registro de mudança nas práticas de negócios e nas relações externas (OECD, 2005).

Apesar de pouca evidência de implantação de inovações gerenciais, outras inovações podem ser reconhecidas. Na tipologia de produto, notam-se uma reforma geral dos chalés, construção de um espaço destinado a eventos e adoção de internet com fibra ótica. $\mathrm{Na}$ tipologia de marketing percebe-se o desenvolvimento de redes sociais como Instagram e Facebook, divulgação por meio de entidades como TripAdvisor e Booking.com. Frente à raridade da inovação gerencial, na próxima pauta foram discutidos quais fatores contribuíram para a adoção e quais teriam exercido o papel contrário.

\subsection{Fatores determinantes}

Primeiramente, os fatores que contribuíram para a adoção da conta contábil destinada às reformas e a parceria com o Sebrae foram do nível individual (LOPES et al., 2018). Ou seja, as características do fundador (gestor) como idade, qualificação, tempo de cargo influenciaram na decisão de inovar. Por estar há muito tempo no cargo de gestor, ser um homem mais vivido e ter uma formação em engenharia eletrônica, Kevin provavelmente aprendeu a planejar reformas e valorizar parcerias.

Por outro lado, também devido a essas mesmas características, vê-se a justificativa da falta de mais inovações. Durante a entrevista, Kevin explicita a vontade de estagnar o crescimento e desenvolvimento da pousada, a fim de evitar riscos e prejuízos. Além disso, pelo extenso tempo que ele está na gestão, já teve experiências com inovações em outros contextos, que atualmente prefere evitar. Por exemplo, em seu primeiro empreendimento em Arraial D'Ajuda, ele precisou pedir ao governo a colocação de um poste, para que em seu estabelecimento tivesse energia elétrica.

Em segundo lugar, os fatores que contribuíram para a adoção do gerenciador de pousadas Desbravador são, em sua maioria, do nível intraorganizacional (LOPES et al., 2018). Esses fatores são: o tipo de organização, por ser uma pousada de médio porte mais tradicional, optou-se pela plataforma acessível, com recursos suficientes para armazenar dados dos hóspedes; tempo de existência da organização é maior que 30 anos, por isso era necessário ter um sistema mais confiável de gerenciamento. Pode-se pensar, adicionalmente, na influência da estrutura organizacional para tal adoção do Desbravador, pois pelas relações de trabalho serem mais familiares e menos rígidas, fica mais fácil à realocação dos funcionários em outras áreas.

Isso posto, vale ressaltar que as decisões de inovar ocorreram de "cima para baixo", conceito explorado na PINTEC (IBGE, 2016). Afinal, foi o gestor quem ansiou, procurou e de fato iniciou os processos inovativos. As consequências de tais decisões serão discutidas no subtópico seguinte. 


\subsection{Consequências}

As consequências das inovações na Pousada Cipó serão expostas de acordo com a entrevista de Kevin. Assim, não houve um instrumento de viés quantitativo que pudesse mensurá-las - dificuldade mencionada no Manual de Oslo (2005).

A conta criada especificamente para a realização de obras teve como desdobramento uma maior folga financeira na empresa. Com tal planejamento, a pousada não precisou realizar dívidas e em longo prazo teve uma demanda maior, uma vez que os quartos ficaram mais bem equipados e mais modernos. Logo, percebe-se uma melhor organização do capital para aplicações e gastos.

A parceria com o Sebrae foi se suma importância para o crescimento dos funcionários, os quais ficaram mais motivados e eficientes após os treinamentos - logo a inovação foi bem sucedida (OECD, 2005). Assim, eles e elas desenvolveram habilidades, que foram aplicadas na rotina da pousada, aumentando a excelência do serviço, e a pousada, ao mesmo tempo, melhorou as relações com entidades externas (OECD, 2018). Com a observação não participante, houve relatos em que os funcionários expressaram a satisfação pelos treinamentos recebidos e percebeu-se uma eficiência no serviço realizado (cômodos todos limpos, agenda com reservas planejadas, sempre um funcionário na recepção à disposição, entre outros).

A adesão do gerenciador de pousadas permitiu à melhora no armazenamento, processamento e análise de dados, consequentemente, a melhora na produção de estatísticas a respeito do cliente (OECD, 2018). Desse modo, o fundador passou a ter uma base para orientá-lo qual fatia de mercado deveria focar e investir mais. Isso permitiu que Kevin tivesse mais tempo para realizar outras tarefas e, simultaneamente, que a pousada ficasse mais competitiva no setor.

Diante do exposto, uma consequência semelhante a todas as inovações foi a disseminação extrafronteiras (IBGE, 2016). Seguindo essa lógica, percebe-se na entrevista com Kevin que tais inovações impactaram outras pousadas localizadas na Serra do Cipó. O fundador relata que após sua adesão ao gerenciador e aos treinamentos do Sebrae viu outras entidades também aderirem. Isso reforça a melhora no compartilhamento e na transferência de conhecimento com outras organizações (OECD, 2018).

Os desdobramentos negativos das inovações gerenciais, portanto, não foram observados nos relatos e registros. Não houve perde de controle da estratégia da empresa, nem do valor do conhecimento. Diante desse cenário, as conclusões de como se dão as inovações gerenciais serão expostas na sessão a seguir.

\section{Considerações finais}

Este artigo cumpriu com o objetivo proposto de apresentar um estudo de caso sobre como ocorrem inovações gerenciais em um meio de hospedagem localizado na Serra do Cipó. As inovações são adotadas tendo em vista a necessidade do meio de hospedagem e a decisão do gestor se relaciona com os fatores intraorganizacionais, macroambientais ou interorganizacionais e individuais. Logo, cada inovação teve diferentes determinantes e em diferentes níveis.

Do mesmo modo que os fatores determinantes contribuíram para o gestor adotar a inovação, eles contribuíram para o oposto. Com isso, estudos futuros podem analisar qual fator foi predominante da não adesão de inovações, a justificativa para a estagnação das 
atividades inovativas por parte da gerência e a relação da personalidade do gestor com o ritmo de inovações empregadas em meios de hospedagem.

Diante dessa perspectiva, a Pousada Cipó não apresentou um grande número de inovações gerenciais principalmente devido à estratégia e ao propósito do líder. Assim, os itens de gestão essenciais são realizados da mesma maneira desde a estruturação da pousada há 36 anos, por exemplo, a contabilidade sempre fora realizada pela mesma empresa terceirizada, pelos mesmos métodos.

Dentre as inovações gerenciais realizadas, observaram-se consequências predominantemente positivas como aumento da eficiência dos funcionários e melhora no processamento de dados. Adicionalmente, tais consequências não tiveram um impacto muito profundo e radical na pousada.

A análise de como se dão as inovações gerenciais na Serra do Cipó ficou limitada a uma única pousada, aos documentos obtidos e à visita ao local. Nesse processo, viu-se que a decisão de inovar ocorre "de cima para baixo", tendo início no cargo de diretoria e que é algo gradual. Além disso, notou-se que os níveis individual, intraorganizacional e macroambiental e interorganizacional dos fatores determinantes influenciaram a decisão da diretoria em adotar as inovações, mas diferindo conforme cada inovação.

Dessa forma, foi possível evidenciar o processo de adoção da inovação gerencial e permitir que novas pautas surgissem para futuras pesquisas. Apesar das limitações, os resultados foram importantes e podem servir como inspiração para outros empreendedores de meios de hospedagem no município de Santana do Riacho ou mesmo em outras localidades. Logo, com o aumento de pesquisas relacionadas à inovação gerencial, o processo de adesão pode ser mais bem compreendido.

Do ponto de vista teórico e metodológico, este artigo contribui com a aplicação de um framework original e uma metodologia adequada à análise de pequenas empresas. Do ponto de vista da agenda de pesquisas, este artigo traz para a ótica da inovação as novidades na gestão e nos formatos organizacionais. Pesquisar inovação gerencial é importante para compreender não somente seus aspectos intrínsecos, mas também as suas interfaces com a inovação tecnológica. Nota-se preocupação cada vez maior com esses aspectos, tal como se percebeu ao trazer neste artigo as novas diretrizes da edição mais recente do Manual de Oslo.

\section{Referências}

BARBOSA, A. et al. Inovações Tecnológicas e Organizacionais em Serviços Intensivo em Conhecimento: Uma Análise Comparativa entre Brasil e Portugal, 2015.

BIRKINSHAW, J.; HAMEL, G.; MOL, M. J. Management innovation. Academy of management Review, v. 33, n. 4, p. 825-845, 2008.

CAETANO, G.; Feira Internacional de Negócios, Inovação e Tecnologia (FINIT), 3ed., 2018.

CREWELL, J. Projeto de Pesquisa: Métodos qualitativo, quantitativo e misto. 2 ed. Porto Alegre: Artmed Editora, 2007. 
CROSSAN, Mary M.; APAYDIN, Marina. A multi-dimensional framework of organizational innovation: A systematic review of the literature. Journal of management studies, v. 47, n. 6, p. 1154-1191, 2010.

DAMANPOUR, F. Footnotes to Research on Management Innovation. Organization Studies, v. 35, n. 9, p. 1265-1285, 2014.

DODGSON, M.; GANN, D. M.; PHILLIPS, N. Perspectives on Innovation Management. In: DODGSON, M.; GANN, D. M.; PHILLIPS, N. The Oxford Handbook of Innovation Management. Oxford: Oxford University Press, 2014.

DRUCKER, Peter. Entrepreneurship and innovation: Practice and principles. New York: Harper Business, 1985.

FAGERBERG, J. Innovation: A Guide to the Literature. In: FAGERBERG, J. et al (Ed.). The Oxford Handbook of Innovation. Oxford: Oxford University Press, 2005.

GIL, A.C. Métodos e técnicas de pesquisa social. São Paulo: Atlas, 1999.

GOMES, G.; NETO, D. D. P. M; GIOTTO, O. T; Análise do conteúdo dos artigos de inovação publicados nos anais do ALTEC, SIMPOI e EnANPAD (2003-2007). Revista de Administração e Inovação. São Paulo, v.8, n.4, p.27-44, out./dez. 2011.

HANSEN, Sten-Olof; WAKONEN, Jouko. Innovation, a winning solution?. International Journal of Technology Management, v. 13, n. 4, p. 345-358, 1997.

IBGE Instituto Brasileiro de Geografia e Estatística. Pesquisa de Inovação - PINTEC 2014. Rio de Janeiro: IBGE, 2016.

LOPES, D.P.T; VIEIRA, N.S.; BARBOSA, A.C.Q.; PARENTE, C.; Management innovation and social innovation: converges and divergences (2017). Academia Revista Latinoamericana de Administración. V.30, Issue: 4, p.474-489, jul/2017.

OECD Organization for Economic Cooperation and Development. Oslo Manual. 3 ed. 2005.

OECD Organization for Economic Cooperation and Development. Oslo Manual. 4 ed. 2018.

SCHUMPETER, J. A. Teoria do Desenvolvimento Econômico. São Paulo: Nova Cultural, 1997[1934].

TIDD, J.; BESSANT, J. Gestão da inovação. 5 ed. Porto Alegre: Bookman, 2015.

VERHOEF, P.; KANNAN, P.; INMAN, J; From Multi-channel Retailing to Omnichannel Retailing: Introduction to the special issue on Multi-channel RetailinG. Journal of Retailing. v.91, issue 2, p.174-181, june 2015. 
VOLBERDA, H. W.; VAN DEN BOSCH, F. A. J.; HEIJ, C. V. Management Innovation: Management as Fertile Ground for Innovation. European Management Review, v. 10, n. 1, p. 1-15, 2013. 